\title{
Kırmızı Kapya Biberlerinin (Capsicum Annuum 1.) Kurutma ve Rehidrasyon Kinetiklerinin Belirlenmesi, Kurutma İşleminin Termodinamik Analizi
}

\author{
Determination of Drying and Rehydration Kinetics of Red \\ Capia Pepper (Capsicum Annuum l.), Energy Analysis of \\ Drying Process
}

\author{
Faruk Kılıç ${ }^{1}$ (1) Tuğba Tabanlıgil Calam ${ }^{2 *}$ \\ ${ }^{1}$ Gazi Üniversitesi, Teknik Bilimler Meslek Yüksekokulu, Makine ve Metal Teknolojileri Bölümü, Ankara, TÜRKiYE. \\ farukkilic@gazi.edu.tr. \\ ${ }^{2 *}$ Gazi Üniversitesi, Teknik Bilimler Meslek Yüksekokulu, Kimya ve Kimyasal İşleme Teknolojileri Bölümü, Ankara, \\ TÜRKIYE. \\ Sorumlu Yazar / Corresponding Author*: ttabanligil@gazi.edu.tr. \\ Geliş Tarihi / Received: 28.03.2019 \\ Araștırma Makalesi/Research Article \\ Kabul Tarihi / Accepted: 23.12.2019 \\ DOI: $10.21205 /$ deufmd.2020226503 \\ Atıf șekli/How to cite: KILIÇ, F., TABANLIGIL, CALAM, T.(2020). Kırmızı Kapya Biberlerinin (Capsicum Annuum I.) Kurutma ve Rehidrasyon \\ Kinetiklerinin Belirlenmesi, Kurutma İşleminin Termodinamik Analizi. DEUFMD 22(65), 331-342.
}

$\ddot{0 ̈ z}$

Bu çalıșmada, kapya biber dilimlerinin kurutma karakteristikleri bir konvektif sıcak havalı kurutucu kullanılarak incelenmiştir. Biberlerin kuruma işleminden önce, sıcak $\mathrm{NaOH}$ çözeltisi ve zeytinyağı $/ \mathrm{K}_{2} \mathrm{CO}_{3}$ karışımı ile ön işleme tabi tutulmuştur. Ön işleme tabi tutulan ve herhangi bir ön işleme tabi tutulmayan biber numuneleri, gıda kurutma fırınında 50 ve $60^{\circ} \mathrm{C}$ sıcaklıklarda kurutulmuştur. Uygulanan ön işlemin ve kurutma sıcaklığındaki artışın, kuruma süresini azalttığı ve rehidrasyon kapasitesini değiștirdiği görülmüștür. $50{ }^{\circ} \mathrm{C}$ sıcaklıkta ön ișlemsiz, $\mathrm{NaOH}$ ve zeytinyağı $/ \mathrm{K}_{2} \mathrm{CO}_{3}$ ön ișlemleri uygulanmasıyla ile kurutulan kapya biberlerin efektif difüzyon katsayıları sirasiyla $1,62 \times 10^{-10}, 3,24 \times 10^{-10}$ ve $8,11 \times 10^{-10} \mathrm{~m}^{2} \mathrm{~s}^{-1}, 60^{\circ} \mathrm{C}$ sicaklıkta ise sirasiyla $3,24 \times 10^{-}$ $10,4,87 \times 10^{-10}$ ve $9,74 \times 10^{-10} \mathrm{~m}^{2} \mathrm{~s}^{-1}$ olarak hesaplanmıştır. Aktivasyon enerjisinin değerleri ise sırasıyla 57,62, 33,88 ve 15,23 kj olarak hesaplanmıştır. Ayrıca kurutma işlemlerinin termodinamik analizleri de yapılarak her bir kurutma sıcaklığı ve uygulanan ön işlemler için kümülatif tüketilen enerji miktarları belirlenmiștir.

Anahtar Kelimeler: Kurutma kinetiği, rehidrasyon kapasitesi, kapya biber, termodinamik analiz, efektif difüzyon katsayısı

\section{Abstract}

In this study, drying characteristics of the capia pepper slices were investigated using a food drying oven. Prior to drying process of the peppers, the peppers were pretreated with a mixture of hot $\mathrm{NaOH}$ solution and olive oil / $\mathrm{K}_{2} \mathrm{CO}_{3}$ mixture. The pre-treated and non-pretreated pepper samples were dried in the food drying oven at temperatures of 50 and $60^{\circ} \mathrm{C}$. It was observed that the applied pretreatment and the increasement in the drying temperature decreased the drying time and changed the rehydration capacity. At $50{ }^{\circ} \mathrm{C}$, the effective diffusion coefficients of the chickens dried by pre- 
treatment with $\mathrm{NaOH}$ and olive oil/ $\mathrm{K}_{2} \mathrm{CO}_{3}$ pretreatments were $1.62 \times 10^{-10}, 3.24 \times 10^{-10}$ and $8.11 \times 10^{-}$ $10 \mathrm{~m}^{2} \mathrm{~s}^{-1}$, respectively. At $60^{\circ} \mathrm{C}$, they were calculated as $3.24 \times 10^{-10}, 4.87 \times 10^{-10}$ and $9.74 \times 10^{-10} \mathrm{~m}^{2} \mathrm{~s}^{-1}$ respectively. Activation energy values were calculated as $57.62,33.88$ and $15.23 \mathrm{kj}$, respectively. In addition, thermodynamic analyzes of drying processes were carried out and cumulative consumed energy amounts were determined for each drying temperature and the pretreatment applied.

Keywords: Drying kinetics, rehydration capacity, capia pepper, thermodynamic analysis, effective diffusion coefficient

\section{Giriş}

Kırmızibiber (Capsicum annuum L.), kanserojen bileșenlere karșı koruma sağlayan ve yașlanma sürecini geciktiren karotenoidler (provitamin A), alkaloidler, $C$ vitamini ve $E$ vitamini içeriği ile fizyolojik sağlı̆̆ teşvik eden özelliklere sahip iyi bir antioksidan madde kaynağıdır [1,2]. Biberler ayrıca kalsiyum, fosfor, potasyum ve demir gibi mineraler içerirler [3]. Kırmızı biberler, çiğ ya da pișmiș olarak tüketilmesinin yanında konserve, turşu, salça, ketcap, sos, hazır çorbalar, konsantre domates çorbaları, tarhana, sucuk, çocuk maması, pastırma yapımı gibi çok geniş bir kullanım alanına sahiptir. Ancak biberin en geniş kullanım alanı kurutularak hazırlanan baharat (toz ve pul biber) halidir ve biber en çok tercih edilen baharatlar arasındadır.

Kurutma, eş zamanlı ısı ve kütle aktarımına bağlı olmak üzere nem giderme işlemi olarak tanımlanmaktadır [4]. Gıda maddelerinin kurutularak saklanması endüstride en çok kullanılan ancak en yoğun enerji gerektiren yöntemlerinden biridir [5]. Kurutma işleminde gıda su aktivitesi değeri düşürülerek ürünün raf ömrünün uzaması sağlanır [6]. Su aktivitesi değerinin belli bir değerin altına düşmesi depolama sırasında gıdanın bozulmasını önler, kalite özelliklerini korur, ürün hacmini azaltarak taşıma ve depolama sırasında kolaylık sağlar [7, 8].

Geleneksel olarak, biberler Türkiye'de açık havada kurutulur ve tam olarak kurumanın sağlanabilmesi için 8-10 gün süren güneș ıșığına maruz kalır. Bu uygulama yaygın bir yöntem olmakla birlikte, zaman alıcıdır. Kuruma sırasında biber, toz, toprak, kum parçacıkları ve böceklerle kirlenmeye karşı eğilimlidir. Ayrıca bu yöntem hava durumuna bağlı olarak her zaman aynı kalitede ürün elde edilememesi gibi bir dezavantaja daha sahiptir $[9,10]$. Tüm bu dezavantajları gidermek amacıyla daha hızlı ve kontrol edilebilen kurutma yöntemleri geliștirilmektedir. Geliștirilen kurutma yöntemleri kullanılarak ürünün kuruma süresinin büyük oranda kısalması ile beraber daha temiz ve standart kalitede kuruma sağlanması, daha az vitamin ve besin kayıpları meydana gelmesi amaçlanmaktadır [11].

Kuruma hızını arttırmak amaciyla gıdaya kuruma öncesinde çeşitli ön işlemler uygulanmaktadır. Kimyasal ön ișlemler gıdanın yüzey geçirgenliğini arttırarak kurutma işlemi sirasında ISı ve nem transferini hızlandırmaktadır. Bunun yanında renk kaybının da önlenmesi amaçlanmaktadır [12]. Haşlama işlemi ile gıdanın hücre duvarının geçirgenliği artarken seçiciliği azalmaktadır. Böylece kuruma esnasında nem atma hızı artmaktadır [12, 13]. Ayrıca oleat esterlerinin alkali veya asit çözeltilerine daldırılan gıdanın renk kayıpları önlenmeye çalışılmaktadır [1416].

Kırmızıbiberin kurutulması çok yaygın olarak yapılan bir ișlem olması nedeniyle yapılan çalışmalarda, kurutma hızını artırmak, bu sırada üründe oluşabilecek kalite kaybını önlemek ve işlem sırasında geçen zamandan ve harcanan enerjiden tasarruf sağlamak amaçlanmaktadır. Pangavhane ve ark. [17], ön ișlem olarak kurutmadan önce yapılan kimyasal daldırma ișleminin kuruma süresini azalttığını ve kuru ürünün renk, lezzet ve besin kalitesini iyileștirdiğini belirtmiștir. Ayrıca yapılan çalışmada $\mathrm{NaOH}$ kullanılarak yapılan ön işlem sonrasında kuruma oranının önemli miktarda arttı̆̆ı gözlemlenmiştir. Christensen ve Peacock [18], gıdanın kurutulması öncesinde yapılan ön işlemde en yaygın olarak kullanılan kimyasalın, zeytinyağı ve potasyum karbonat $\left(\mathrm{K}_{2} \mathrm{CO}_{3}\right)$ karışımı, ya da etil oleat gibi etil ester ve $\mathrm{K}_{2} \mathrm{CO}_{3}$ 'ün bir karıșımı olduğunu belirtmektedir. Kullanılan bu karışım, gıdanın su difüzyonuna karşı iç direncinin azalmasını sağlamaktadır.

Literatürde kurutma ișlemi için yapılan kimyasal ön işlemlerde sıklıkla etil oleat $/ \mathrm{K}_{2} \mathrm{CO}_{3}$ karıșımı kullanılmaktadır. Bu çalışmada etil oleat yerine literatürdeki kullanımı kısıtlı olarak yer alan 
zeytinyağı $/ \mathrm{K}_{2} \mathrm{CO}_{3}$ karıșımı kullanılmıștır. Zeytinyağ $1 / \mathrm{K}_{2} \mathrm{CO}_{3}$ karıșımının kullanımı, hem maliyetinin daha düşük olması hem de temin edilirliğinin kolaylığı açısından avantajlıdır. Ayrıca bu çalışmada, literatürdeki yeri kısıtlı olan, ön işlem uygulanarak yapılan kurutma işlemlerinde termodinamik analize yer verilmiștir.

$\mathrm{Bu}$ çalışmada herhangi bir ön işlem uygulanmamış olan kapya biberler ile bazik ortamda haşlama ve zeytinyağ $\breve{I}_{1} / \mathrm{K}_{2} \mathrm{CO}_{3}$ karışımında bekletme şeklinde kimyasal ön işlemler uygulanan kapya biberlerin 50 ve $60^{\circ} \mathrm{C}$ sıcaklıklarında kuruma kinetiği incelenmis ve birbiri ile karşılaştırılmıştır. Her bir kurutma ișlemi için efektif difüzyon katsayısı (Deff) ve aktivasyon enerjisi hesaplanmıș, rehidrasyon kapasiteleri belirlenmiștir. Ayrıca kurutma işlemlerinin termodinamik analizleri de yapılarak 50 ve $60{ }^{\circ} \mathrm{C}$ kurutma sıcaklığı ve uygulanan ön ișlemler için kümülatif tüketilen enerji miktarları belirlenmiștir. Yapılan termodinamik analizle ön işlem uygulaması sonucunda, kurutma ișleminde harcanan zamanın yanı sıra enerjiden sağlanan \% tasarruf değerleri tespit edilmiș ve yapılan ön işlemler birbiri ile karşılaștırılmıștır.

\section{Materyal ve Metot}

\subsection{Kapya biberlerin kurutma işlemine hazırlanması}

Bu çalışmada, bir süpermarketten satın alınan kapya biberleri kullanılmıştır. Kapya biberler eni ve boyu $1,5 \mathrm{~cm}$ olacak șekilde bir bıçak yardımıyla dilimlenmiş ve her birinin ağırlığ $100 \mathrm{~g}$ olan üç gruba ayrılmıştır. Bunlardan ilkine hiçbir ön işlem uygulanmamıştır. Diğeri $90^{\circ} \mathrm{C}$ sıcaklığındaki kütlece \% 0,5'lik $\mathrm{NaOH}$ çözeltisi içerisinde $10 \mathrm{~s}$ süre ile bekletilip çıkarılmıș ve üzerine $\mathrm{NaOH}$ çözeltisinden gelen kalıntıları gidermek için saf su ile yıkanmıștır. Son grup ise $25{ }^{\circ} \mathrm{C}$ sıcaklığında kütlece $\% 4$ zeytinyağı ve $\% 5$
$\mathrm{K}_{2} \mathrm{CO}_{3}$ içeren karıșımda 15 dakika bekletilerek ön işleme tabi tutulmuş ve bu işlemin ardından kurutmaya alınmıştır.

\subsection{Kurutma deneyleri}

$\mathrm{Bu}$ çalıșmada en, boy ve yüksekliği sırasıyla $0.42 \mathrm{~m}^{*} 0.60 \mathrm{~m}^{*} 0.38 \mathrm{~m}$ olan kurutucu kullanılmıştır. Isıtılan firın hacmi $0.0846 \mathrm{~m}^{3}$ tür. Kuruma parametrelerini belirleyebilmek için fırının ortam sıcaklığı ve nemi ile gıdanın ağırlığı kurutma esnasında kaydedilmiștir. Nem sensörü (DHT11) firın içi bağıl nemini, termokupl ise ortam sıcaklığını ölçmektedir. DHT11 düşük maliyetli dijital sıcaklık ve nem sensörüdür. Termokupl ise sıcaklık sensörüdür. $-20^{\circ} \mathrm{C}$ ile 85 ${ }^{\circ} \mathrm{C}$ ölçüm aralığında ve $0.25{ }^{\circ} \mathrm{C}$ hassasiyete çalışmaktadır. Gıda kurutma firını için uygun sıcaklık aralığına sahip ve ucuz elde edilebilen geleneksel $\mathrm{K}$ tipi termokupl kullanılmıştır. $\mathrm{Bu}$ ölçümler mikro-denetleyici içeren arduino kartı yardımı ile yapılmıștır. Bu kart yazılım ile ölçümleri bilgisayar ortamına kaydetmektedir.

Kurutma parametrelerini belirlemek için ürünün ağırlı̆̆ını ölçmek gerekmektedir. Ancak kurutma sırasında ürünün kurutucudan çıkartılıp hassas terazide tartılması ve tekrar firının içerisine yerleştirme işlemi hem ölçümün hata miktarını arttırmakta hem de enerji kaybına yol açmaktadır. Böylece meydana gelebilecek hatayı azaltmak amacıyla kurutma sırasında ürünün ağırlığı, fırının içerisine bir yük hücresi yerleştirilerek anlık olarak ölçülmüştür. Deney düzeneğinde HT Sensör Teknolojisi TAL201 model yük hücresi kullanılmıștır. HX711 kartı, basit haberleşme ara yüzüne sahip olup çok hassas ölçümler yapabilmektedir. Yük hücresi baskı fiziksel parametresini basit elektronik bir sinyale dönüştüren sensördür. Yapılan yazılım sayesinde ve yük hücresi yardımı ile gıda kurutucudan çıkartılmadan istenilen zaman aralığında hassas olarak tartılmıştır. 
DEÜ FMD 22(65), 331-342, 2020

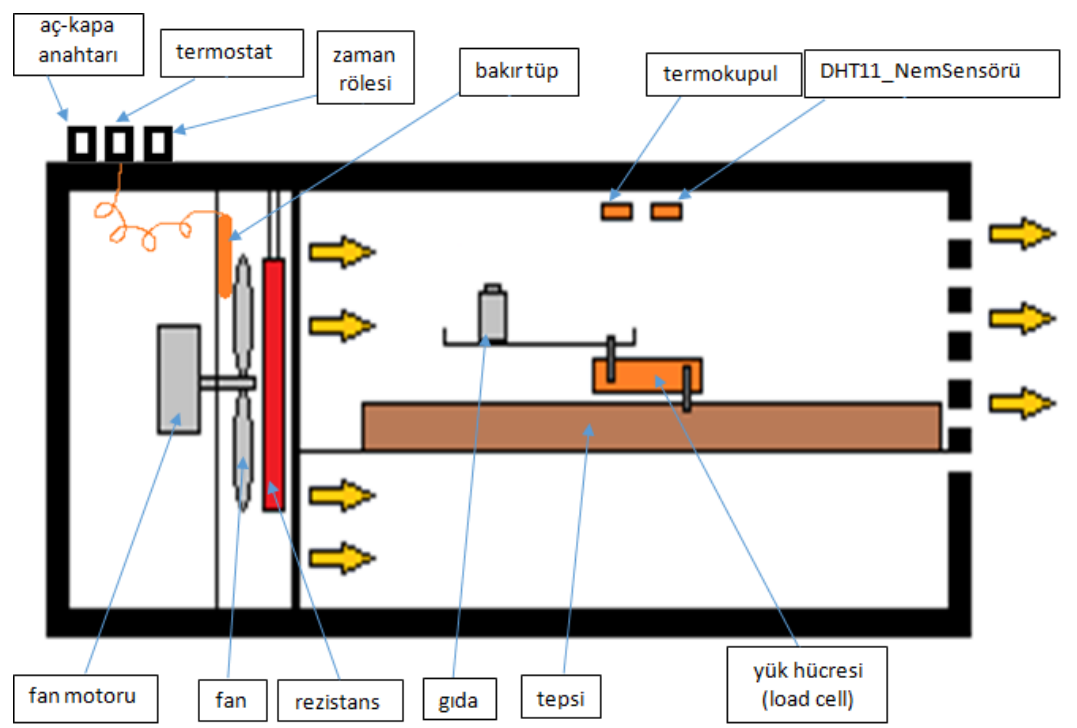

Şekil 1. Konvektif sıcak havalı kurutucu

Kurutma ișleminden önce uygulanan ön işlemlerde isıtıcı olarak Mtops marka MS300HS model ısıtıcılı manyetik karıștırıcı kullanılmıștır.

Kurutma ișleminden sonra elde edilen kuru kırmızıbiberin rehidrasyon kapasitesi ölçümleri sırasında ürünlerdeki ağırlık değişimleri için Kern marka ABJ 220-4 NM model dijital hassas terazi ile her 15 dakikada bir kaydedilmiștir. Terazi $10 \mathrm{mg}$ ile $200 \mathrm{~g}$ arasinda, 0,1 mg hassasiyette ölçüm yapabilmektedir.

\subsection{Nem içeriği ve kurutma hızının hesaplanması}

Kurutma işlemi süresince, kullanılan kırmızıbiberlerin nem oranı (yaș baz) (MR) aşağıdaki eşitlik (Eş. 1) kullanılarak hesaplanmıștır $[19,20]$.

$M R=\frac{M_{t}-M_{e}}{M_{o}-M_{e}}$

Bu eșitlikte MR: nem oranı, $\mathrm{M}_{\mathrm{t}}$ : $\mathrm{t}$ anındaki nem içeriği (kg $\mathrm{H}_{2} \mathrm{O} / \mathrm{kg}$ kuru madde), $\mathrm{Me}_{\mathrm{e}}$ Kurutma koșullarındaki havanın denge nem içeriği $(\mathrm{kg}$ $\mathrm{H}_{2} \mathrm{O} / \mathrm{kg}$ kuru madde), $\mathrm{M}_{0}$ : Ürünün kurutmaya başlamadan önceki nem içeriğidir $\left(\mathrm{kg} \mathrm{H}_{2} \mathrm{O} / \mathrm{kg}\right.$ kuru madde).Eș. 1'de $M_{e}$ 'nin değeri $M_{t}$ veya $M_{0}$ ile karşılaştırıldığında nispeten küçüktür. Bu nedenle Eș. 1 basitleștirilerek Eș. 2 elde edilmiştir.

$M R=\frac{M_{t}}{M_{o}}$

Kurutma hızı ise Eş. 3 yardımıyla hesaplanmıștır.
$\frac{\Delta M}{\Delta t}=\lim _{\Delta t \rightarrow 0} \frac{M_{t+\Delta t}-M_{t}}{\Delta t}$

Eş. 3'de t: süre (dakika) , $M_{t+\Delta t}: t+\Delta t$ anındaki nem içeriği ( $\mathrm{kg} \mathrm{H}_{2} \mathrm{O} / \mathrm{kg}$ kuru madde) olarak ifade edilmektedir.

\subsection{Efektif difüzyon katsayısı ve aktivasyon enerjisinin hesaplanması}

Efektif difüzton katsayısı $D_{\text {eff }}\left(\mathrm{m}^{2} / \mathrm{s}\right)$, kurutulan sebzenin kaybettiği nemin taşınımıyla ilişkili önemli bir kinetik parametredir [21]. Gıda maddelerinin ince tabaka kurutma parametreleri Fick'in difüzyon eșitliği kullanılarak tanımlanabilir $[22,23]$. Efektif difüzyon katsayısı, gıda kurutma işlemlerinde önemli parametrelerden biridir. Kapya biberlerin ön işlem uygulanmadan ve uygulanarak kurutulması işlemleri için hesaplanmıştır. İlk nem içeriğinin homojen olduğu ve difüzyon katsayısının sabit olduğu dilim şeklinde kesilen sebze için Crank tarafından aşağıdaki eşitlik elde edilmiştir [24].

$M R=\frac{8}{\pi^{2}} \sum_{n=0}^{\infty} \frac{1}{(2 n+1)^{2}} \exp \left(\frac{-(2 n+1)^{2} \pi^{2} D_{e f f} t}{4 L^{2}}\right)$ (4)

Eş. 4'de MR: nem oranı, $\mathrm{M}_{\mathrm{t}}$ : $\mathrm{t}$ anındaki nem içeriği (kg $\mathrm{H}_{2} \mathrm{O} / \mathrm{kg}$ kuru madde), $\mathrm{M}_{\mathrm{e}}$ : Kurutma koşullarındaki havanın denge nem içeriği (kg $\mathrm{H}_{2} \mathrm{O} / \mathrm{kg}$ kuru madde), $\mathrm{M}_{0}$ : Ürünün kurutmaya başlamadan önceki nem içeriği $\left(\mathrm{kg} \mathrm{H}_{2} \mathrm{O} / \mathrm{kg}\right.$ kuru madde), Deff: difüzyon katsayısı $\left(\mathrm{m}^{2} / \mathrm{s}\right)$, L: kurutulan ürünün yarı kalınlığı $(\mathrm{m})$, t: kurutma süresi (s) olarak ifade edilir. Eş. 4. uzun kuruma 
süreleri için serinin ilk terimi alınarak basitleştirilirse ve Eş. 5. halini alır [25];

$M R=\frac{8}{\pi^{2}} \exp \left(\frac{-\pi^{2} D_{e f f} t}{4 L^{2}}\right)$

Kurutma süresine karşı çizilen ln (MR)

grafiğinin eğimi k olmak üzere, Eș. 6'ya göre $D_{\text {eff }}$ hesaplanmıştır.

$D_{\text {eff }}=\frac{4 k L^{2}}{\pi^{2}}$

Efektif difüzyon katsayısının değișimi Arrhenius tipi üssel bir fonksiyonla açıklanmaktadır. Aktivasyon enerjisi Eș. 7. kullanılarak hesaplanabilir [26]. Gerçekleşen bir prosesin aktivasyon enerjisinin yüksek ise, o prosesin sıcaklık değișimine daha duyarlı olduğunu söylenebilir [27].

$D_{\text {eff }}=D_{0} \exp \left(-\frac{E_{a}}{R T}\right)$

Eş. 7'de Deff: Efektif difüzyon katsayısı ( $\left.\mathrm{m}^{2} / \mathrm{s}\right), \mathrm{D}_{0}$ : sonsuz sıcaklıkta difüziviteye eșdeğer bir sabit $\left(\mathrm{m}^{2} / \mathrm{s}\right)$, R: Gaz sabiti $(8,314 \mathrm{~kJ} /(\mathrm{mol} \times \mathrm{K}))$, Ea: Aktivasyon enerjisi $(\mathrm{kJ} / \mathrm{mol})$ ve $\mathrm{T}$ : kurutma sıcaklığıdır (Kelvin). Eş. 7 'ye göre sıcaklığa karşı $\ln D_{\text {eff }}$ grafiğinden elde edilen doğrunun eğimi aktivasyon enerjisi değerini verir.

\subsection{Rehidrasyon kapasitesinin ölçülmesi (Measurement of rehydration capacity)}

Rehidrasyon kapasitesi (RC), kurutma sonrasında elde edilen ürünün kalite ölçütlerinden biridir ve kurutma koșulları, ön işlem, suyun sıcaklığı, süre ve örnek yapısından etkilenir [28]. Kurutulmuş gıda maddesinin rehidrasyon kapasitesi, onun suda belirli bir sürede belirli koșullarda bekletilmesi sonucunda kazandığı su miktarı ile belirlenir [29]. Sabit tartıma getirilen beherlere $400 \mathrm{~mL}$ saf su ilave edilmiştir. Rehidrasyon denemeleri sabit $25{ }^{\circ} \mathrm{C}$ ve $50{ }^{\circ} \mathrm{C}$ sıcaklıklarda yapılmıștır. İlk ağırlıkları bilinen kuru biber örnekleri hazırlanan sulara atılmıștır. 15 dakikada zaman periyotlarında çıkarılıp kurulama kâğıdıyla kurulandıktan sonra ağırlıkları ölçülmüştür. Ürünlerdeki ağırlık değișimleri için Kern marka ABJ 220-4 NM model dijital hassas terazi kullanılmıştır. Elde edilen verilerden yararlanarak Eş. 8 ile rehidrasyon kapasitesi değerleri hesaplanmıștır.

$R C=\frac{W_{2}-W_{1}}{W_{1}}$

Eş. 8'de $W_{1}$ ve $W_{2}$ simgeleri sırasıyla rehidrasyon ișleminden önceki ve sonraki madde miktarını $(\mathrm{kg})$ ifade etmektedir.

\subsection{Termodinamik analiz}

Kullanılan kurutucuda kurutma işleminin yapılabilmesi için ısıtıcı rezistans üzerinden $W_{\mathrm{r}}$ kadar enerji verilmiştir. Fırın içindeki ısının homojen dağılımının sağlanabilmesi için rezistansla eș zamanlı bir fan çalıșmaktadır ve bu fan $W_{\mathrm{f}}$ kadar enerji harcamaktadır. Fırının kapalı hacminin duvarlarından isı transferiyle $Q_{\mathrm{d}}$ kadar enerji atılmaktadır. Kuruyan gıda $Q_{\mathrm{g}}$ kadar enerji almaktadır. Aynı zamanda firın kapağının kenarlarından $Q_{\mathrm{k}}$ kadar ısıl kaçaklar olduğu kabul edilmiștir. Çalışma boyunca fırın iç sıcaklığı sabit tutulmuştur bir termometre ile kontrol edilmiştir. Termodinamiğin 1. yasasına göre, kullanılan kurutucunun isitılması için harcanan toplam enerji ve kurutma ișlemi için harcanan toplam enerjiler arasındaki ilişki Eș. 9 ile gösterilebilir.

$W_{f}-W_{r}-Q_{k}-Q_{g}-Q_{d}=0$

Eş. 9'da $Q_{k}, Q_{g}$ ve $Q_{d}$ simgeleri ile gösterilen isı değerlerinin genel formülü Eș. 10, Eș. 11 ve Eș. 12 ile verilir.

$Q_{k}=m_{k} c_{k} \Delta t$

$Q_{g}=m_{g} c_{g} \Delta t$

$Q_{d}=m_{d} c_{d} \Delta t$

Çalışmada kurutma için harcanan enerji miktarını tespit edebilmek için Köhler marka monofaze aktif sayaç kullanılmıştır. Kullanılan sayacın çalışma sıcaklık aralığ arasındadır. Frekans değeri $50 \mathrm{~Hz}$ ve referans voltajı 220 V'dur.

\section{Bulgular}

\section{1. Ön işlem ve kurutma sıcaklığının kurutma süresine etkisi}

Kapya biberlerin kurutma karakteristikleri 50 ve $60{ }^{\circ} \mathrm{C}$ kurutma sıcaklığında incelenmiștir. Biberler \% 6 son nem içeriğine kadar kurutulmuştur [30]. Tablo 1 'de, 50 ve $60{ }^{\circ} \mathrm{C}$ sıcaklıklarda kurutulmuş kapya biber dilimlerinin kurutma süreleri gösterilmektedir. Tablo 1'de, kapya biberlerin $50{ }^{\circ} \mathrm{C}$ 'de ön işlem uygulanmadan kurutma süresi 420 dakika, $\mathrm{NaOH}$ ve Zeytinyağ $1 / \mathrm{K}_{2} \mathrm{CO}_{3}$ ön ișlemleri uygulanmasıyla kurutma süresi sırasıyla 255 ve 150 dakikaya düșmüștür. $50{ }^{\circ} \mathrm{C}$ 'de $\mathrm{NaOH}$ ve Zeytinyağı $/ \mathrm{K}_{2} \mathrm{CO}_{3}$ ön işlemleri uygulanmasıyla kurutma süresi sırasıyla \% 39,28 ve $\% 64,28$ oranında azalmıștır. $60{ }^{\circ} \mathrm{C}^{\prime}$ de ise ön ișlem uygulanmadan kurutma süresi 330 dakika 
DEÜ FMD 22(65), 331-342, 2020

olmuș, $60{ }^{\circ} \mathrm{C}^{\prime}$ de $\mathrm{NaOH}$ ve zeytinyağ ${ }_{1} / \mathrm{K}_{2} \mathrm{CO}_{3}$ ön işlemleri uygulanmasıyla kurutma süresi sirasıyla \% 40,91 ve \% 59,09 oranında azalmıştır.

Uygulanan ön işlemler ile her iki sıcaklık için kurutma sürelerinde anlamlı düşüşler gerçekleşmiştir. Uygulanan işlemlerden Zeytinyağ $1 / \mathrm{K}_{2} \mathrm{CO}_{3}$ uygulamasının kapya biberlerinin kuruma süresini kısaltmada en etkili yöntem olduğu anlaşılmıștır. Ayrıca sıcaklık artıșıyla da her bir ișlem için kurutma sürelerinde azalma gerçekleşmiştir. Sıcaklık artışı sonucunda kurutma havasındaki bağıl nem oranındaki düşüşün, kurutma süresindeki azalmaya sebep olduğu düşünülmüștür. Dolayısıyla sıcaklık artışı kurutmada çok etkin bir rol üstlenmektedir.

Tablo 1. Kapya biberlerin kurutma süreleri

\begin{tabular}{lll}
\hline $\begin{array}{l}\text { Sicaklık } \\
\left({ }^{\circ} \mathrm{C}\right)\end{array}$ & Uygulanan İşlem & $\begin{array}{l}\text { Süre } \\
\text { (dakika) }\end{array}$ \\
\hline \multirow{2}{*}{50} & Ön işlemsiz & 420 \\
\cline { 2 - 3 } & $\mathrm{NaOH}$ & 255 \\
\cline { 2 - 3 } & Zeytinyağı $/ \mathrm{K}_{2} \mathrm{CO}_{3}$ & 150 \\
\hline \multirow{3}{*}{60} & Ön işlemsiz & 330 \\
\cline { 2 - 3 } & NaOH & 195 \\
\cline { 2 - 3 } & Zeytinyağı $/ \mathrm{K}_{2} \mathrm{CO}_{3}$ & 135 \\
\hline
\end{tabular}

\section{2. Ön işlem ve kurutma sıcaklığının nem oranına ve kurutma hızına etkisi}

Kalınlığı ve kapladığı yüzey alanı eşit olan kapya biberlerin 50 ve $60{ }^{\circ} \mathrm{C}$ sicaklıklarda ön ișlemsiz, $\mathrm{NaOH}$ ve Zeytinyağ $\breve{1}_{2} / \mathrm{K}_{2} \mathrm{CO}_{3}$ ön işlemleri ile kurutulma işlemleri için nem oranı ve kuruma hızı değerleri Eş. 2 ve Eş. 3 kullanılarak hesaplanmıștır. Nem oranının kurutma süresine karşı grafiği Şekil 2'de, kurutma hızının nem içeriğine karşı grafiği ise Şekil 3'de verilmiştir. Şekil 2 incelendiğinde uygulanan her bir yöntem için $60{ }^{\circ} \mathrm{C}$ kurutma sıcaklığı uygulamasındaki nem oranı düșüşünün, $50{ }^{\circ} \mathrm{C}$ uygulamasına göre daha fazla olduğu görülmektedir. Ayrıca her iki sıcaklık için, nem oranındaki düşüş en hızlı zeytinyağ $1 / \mathrm{K}_{2} \mathrm{CO}_{3}$ uygulamasında, en yavaș düşüş ön işlemsiz kurutma işleminde gerçekleşmektedir. Şekil 3'de kurutma hızının sıcaklık artışıyla arttığı, en yüksek kurutma hızının $\quad 60 \quad{ }^{\circ} \mathrm{C}$ 'de zeytinyağ ${ }_{1} / \mathrm{K}_{2} \mathrm{CO}_{3}$ uygulamasında, en düşük kurutma hızının ise 50 ${ }^{\circ} \mathrm{C}$ 'de ön ișlemsiz kurutma işleminde olduğu görülmektedir. Şekil 2 ve 3'den sicaklığın artışının ve uygulanan ön işlemin kapya biberin kurutma kinetiği üzerinde çok etkili olduğu ve en etkili ön işlemin zeytinyağ $\breve{I}_{1} / \mathrm{K}_{2} \mathrm{CO}_{3}$ uygulaması olduğu görülmektedir. 
DEÜ FMD 22(65), 331-342, 2020

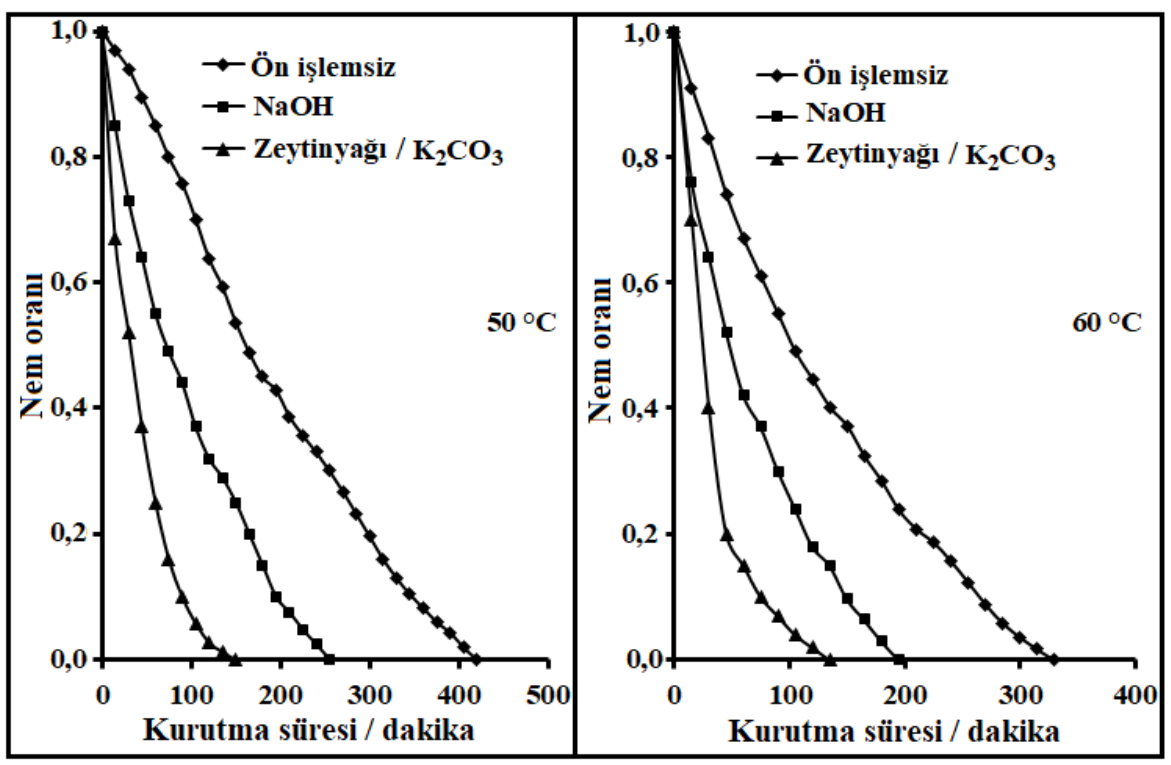

Şekil 2. Kapya biberlerin $50{ }^{\circ} \mathrm{C}$ ve $60^{\circ} \mathrm{C}$ sıcaklıklardaki kuruma işleminde nem oranının kurutma süresine karşı grafiği

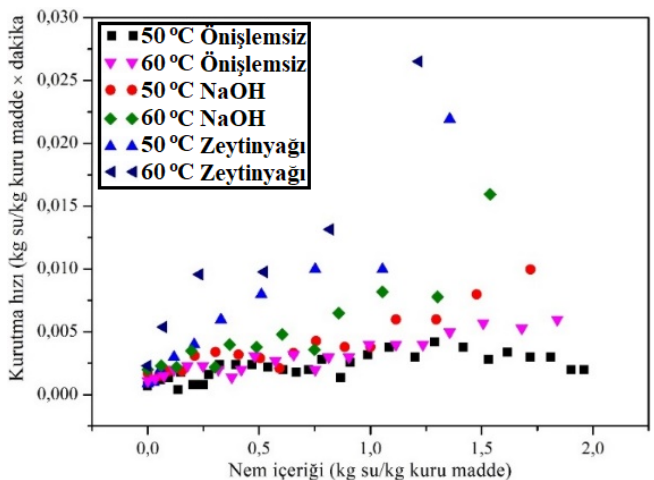

Şekil 3. Kapya biberlerin $50{ }^{\circ} \mathrm{C}$ ve $60{ }^{\circ} \mathrm{C}$ sıcaklıklardaki kuruma işleminde kuruma hızının nem içeriğine karşı grafiği

\subsection{Efektif difüzyon katsayısı}

50 ve $60{ }^{\circ} \mathrm{C}$ sıcaklıklarda ön işlemsiz, $\mathrm{NaOH}$ ve Zeytinyağ $\breve{l}_{1} / \mathrm{K}_{2} \mathrm{CO}_{3}$ ön ișlemleri ile kurutulan kapya biberlerin efektif difüzyon katsayıları Eş. 6 kullanılarak hesaplanmış ve Şekil 4'de verilmiștir. $50{ }^{\circ} \mathrm{C}$ sıcaklıkta ön ișlemsiz, $\mathrm{NaOH}$ ve Zeytinyağı $/ \mathrm{K}_{2} \mathrm{CO}_{3}$ ön işlemleri uygulanmasıyla ile kurutulan kapya biberlerin efektif difüzyon katsayıları sirasıyla $1,62 \times 10^{-10}, 3,24 \times 10^{-10}$ ve $8,11 \times 10^{-10} \mathrm{~m}^{2} / \mathrm{s}, \quad 60{ }^{\circ} \mathrm{C}$ sicaklıkta ise sirasiyla $3,24 \times 10^{-10}, 4,87 \times 10^{-10}$ ve $9,74 \times 10^{-10} \mathrm{~m}^{2} \mathrm{~s}^{-1}$ olarak hesaplanmıştır. Deneysel olarak elde edilen efektif difüzyon katsayısı değerlerinin literatürde belirtilen difüzyon katsayısı değerleri değerleri 10-10 - 10-9 $\mathrm{m}^{2} / \mathrm{s}$ aralı̆̆ ile uyumlu olduğu tespit edilmiştir.

Kurutma sıcaklığının artmasıyla birlikte ön işlemsiz ve $\mathrm{NaOH}$ ve Zeytinyağl $/ \mathrm{K}_{2} \mathrm{CO}_{3}$ ön ișlemleri ile kurutulmuș kapya biberlerin efektif difüzyon katsayısı değerleri artmaktadır. $\mathrm{Bu}$ durum, yüksek sıcaklıklarda kapya biber içerisindeki nemin daha kolay ve hızlı buharlaşmasıyla açıklanabilir. Ayrıca aynı sıcaklık değeri için zeytinyağ $1 / \mathrm{K}_{2} \mathrm{CO}_{3}$ uygulanarak kurutulan kapya biberlerin en hızlı kuruduğu, bunu $\mathrm{NaOH}$ uygulanarak kurutulan kapya biberlerin takip ettiği ve en düşük efektif difüzyon katsayısına ön işlemsiz kurutulan kapya biberlerin sahip olduğu görülmüştür.

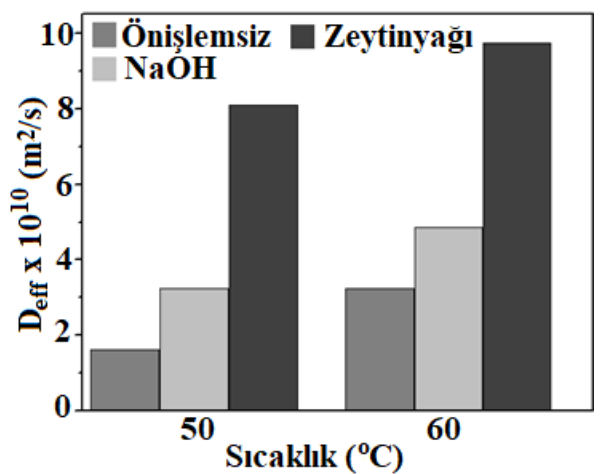

Şekil 4. Kapya biberlerin efektif difüzyon katsayıları 


\subsection{Aktivasyon enerjisi}

Aktivasyon enerji değerleri, Şekil 5'de verilen $1 /(\mathrm{T}+273,15)^{\prime}$ ye karşı çizilen $\ln \mathrm{D}_{\text {eff }}$ grafiklerinin doğru denklemlerinden yararlanarak hesaplanmıştır. Așağıdaki eșitliklerde ön işlem uygulanmadan (Eş. 13), $\mathrm{NaOH}$ uygulanarak (Eș. 14) ve zeytinyağl $/ \mathrm{K}_{2} \mathrm{CO}_{3}$ uygulanarak (Eş. 15) kurutulan kapya biberleri için sıcaklığın difüzyon katsayı değerlerine etkisi gösterilmiştir.

Ön işlemsiz kurutulan kapya biberlerde;

$D_{\text {eff }}=\exp \left(-\frac{6931}{T}\right)+0,347$

$\mathrm{NaOH}$ çözeltisine tabi tutulmuş kapya biberlerde;

$D_{\text {eff }}=\exp \left(-\frac{4075}{T}\right)+9,92 \times 10^{-5}$

Zeytinyağ $/ \mathrm{K}_{2} \mathrm{CO}_{3}$ tabi tutulmuş kapya biberlerde;

$D_{\text {eff }}=\exp \left(-\frac{1832}{T}\right)+3,37 \times 10^{-7}$

Eş. 9, Eş 10 ve Eş. 11'den yararlanarak ön işlemsiz, $\mathrm{NaOH}$ ve Zeytinyağı/K2CO3 ön işlemleri ile kurutulan kapya biberlerin aktivasyon enerjileri sırasıyla 57,62, 33,88 ve 15,23 kj olarak hesaplanmıștır. Bu çalışmada hesaplanan aktivasyon enerji değerleri daha önce yapılan ve literatürde yer alan veriler $[31,32]$ ile uyum göstermektedir.

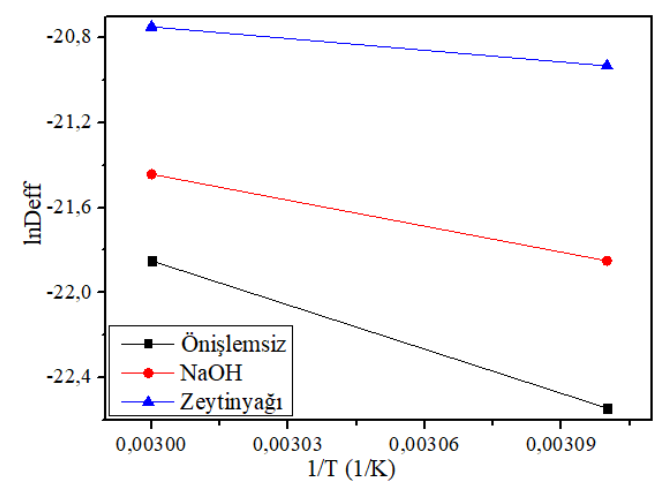

Şekil 5. Sıcaklığın efektif difüzyon katsayısı üzerindeki etkisi

\subsection{Rehidrasyon kapasitesi}

Rehidrasyon işlemi kurutma yöntemi, uygulanan ön işlemler, gıdanın fiziksel yapısı ve kimyasal bileşimi gibi çok çeşitli faktörlerden etkilenen bir ișlemdir [33]. Kurutulan kapya biberlerin rehidrasyon kapasitelerini bulmak için $50^{\circ} \mathrm{C}^{\prime} \mathrm{de}$ deneyler yapılmış ve elde edilen veriler (8) eșitliğinden yararlanılarak hesaplanmıștır. Şekil $6^{\prime}$ da $50^{\circ} \mathrm{C}$ rehidrasyon sıcaklığında 50 ve $60^{\circ} \mathrm{C}$ sıcaklıklarda ön işlem uygulanmadan kurutulmuş kapya biberlerinin rehidrasyon kapasiteleri sirasıyla 4,07 ve 5,39 kg su/kg kuru madde, $\mathrm{NaOH}$ çözeltisinde bekletildikten sonra kurutulmuş kapya biberlerinin rehidrasyon kapasiteleri sırasıyla 5,27 ve 6,27 kg su/kg kuru madde, zeytinyağl $/ \mathrm{K}_{2} \mathrm{CO}_{3} \quad$ karışımında bekletildikten sonra kurutulmuş kapya biberlerinin rehidrasyon kapasiteleri sırasiyla 6,43 ve $6,65 \mathrm{~kg} \mathrm{su} / \mathrm{kg}$ kuru madde olarak elde edilmiştir. Kurutma işleminden önce uygulanmış olan ön işlemlerin rehidrasyon kapasitelerini etkilediği görülmüştür. Rehidrasyon kapasitesi değeri en fazla zeytinyağı $/ \mathrm{K}_{2} \mathrm{CO}_{3}$ ön işlemi uygulanan, en az ise ön işlem uygulanmamış olan kapya biberlerde elde edilmiştir. Şekil 6'da görüldüğü gibi, kurutma sıcaklığının artmasıyla rehidrasyon kapasitesinde artış olmuştur. Elde edilen veriler Vega-Gálvez ve ark. [34] ile Marques ve arkadaşlarının [35] elde ettiği sonuçlar ile uyumludur.

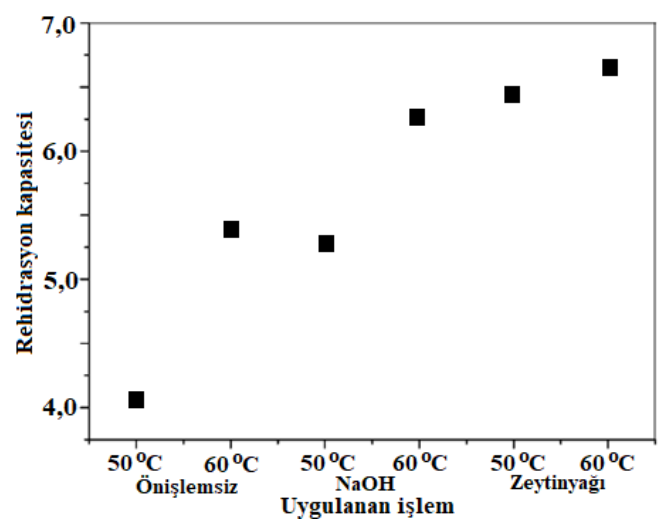

Şekil 6. Uygulanan ön işlemlere bağlı olarak değișen kuru kapya biberlerin rehidrasyon kapasiteleri grafiğ $\mathrm{i}$

\subsection{Termodinamik analiz}

Kapya biberlerin kurutulması işlemleri için kurutma süresine karşı çizilen enerji tüketim grafikleri Şekil 7'de gösterilmiștir. Uygulanan kurutma işlemlerinde, fırının ilk 30 dakikadaki ısıtılmasında yaklaşı $0,160 \quad \mathrm{kWh}$ enerji harcanmıştır. Isıtmanın ilk 30 dakikasında tüketilen enerjinin yüksek olmasının sebebi, fırın sıcaklığının, fırın içi hava sıcaklığının ve kurutulacak ürün sıcaklığının henüz ortam sıcaklığında olup, hedeflenen kurutma 
sıcaklığından düşük olmasıdır. Fırın sıcaklığının, fırın içi hava sıcaklığının ve kurutulacak ürün sıcaklığının, hedeflenen kurutma sıcaklığına ulaşması ile beraber elektrik tüketim değerleri daha kararlı hale gelmiștir. Şekil 7'de, $60^{\circ} \mathrm{C}$ sıcaklığında yapılan kurutma işlemlerinin tümünde tüketilen enerji, $50{ }^{\circ} \mathrm{C}$ sicaklığında yapılan kurutma işlemlerinde tüketilen enerjiden daha fazladır. Ön işlem uygulanmadan ve uygulanarak yapılan kurutma işlemlerinin her birinde, kurutma sıcaklığının artışı ile kuruma süresinin azaldığı ancak tüketilen enerjinin arttığı görülmektedir.

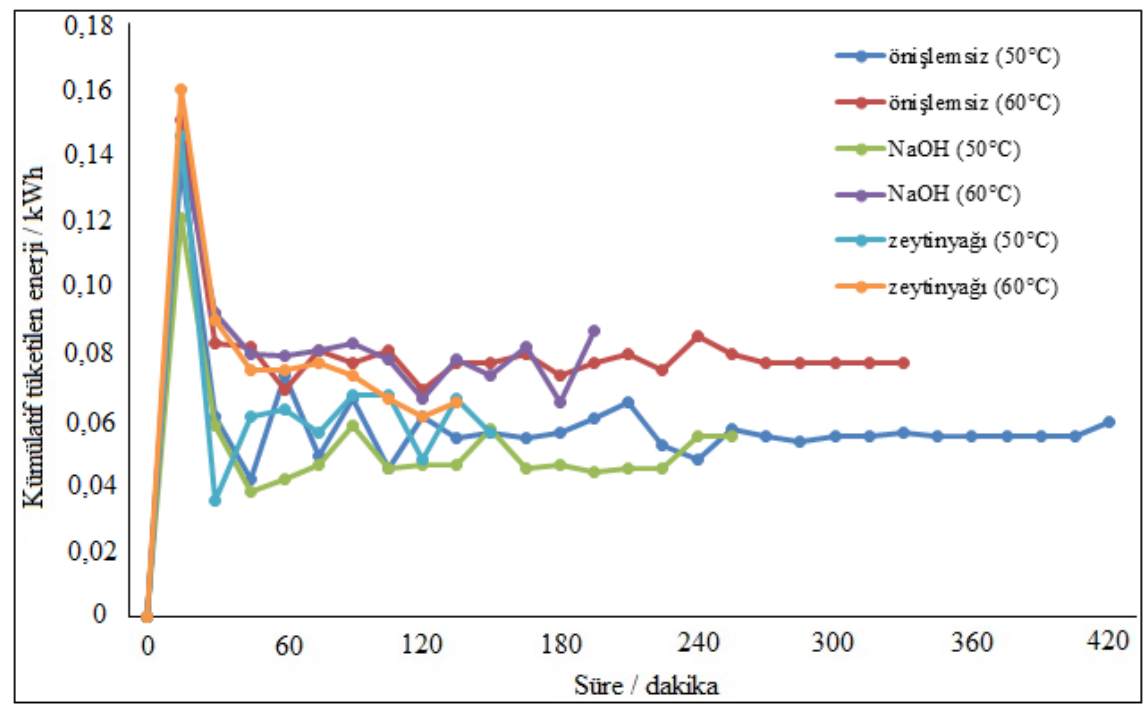

Şekil 7. Kapya biberlerinin kurutulma işlemlerinde zamana karşı çizilen enerji tüketim grafiği

Şekil 7'de kurutma süresine karşı çizilen kümülatif tüketilen enerji grafikleri verilmiștir. Buna göre, $50{ }^{\circ} \mathrm{C}$ ve $60{ }^{\circ} \mathrm{C}$ sicaklıklarında ön işlemsiz olarak yapılan kurutma işlemlerinde sırasıyla 1,645 ve $1,782 \mathrm{kWh}, \mathrm{NaOH}$ çözeltisinde haşlama ön işlemi uygulanarak yapılan kurutma işlemlerinde sırasıyla 0,867 ve 1,084 $\mathrm{kWh}$, zeytinyağı $/ \mathrm{K}_{2} \mathrm{CO}_{3}$ ön işlemi uygulanarak yapılan kurutma işlemlerinde ise sırasıyla 0,680 ve $0,742 \mathrm{kWh}$ enerji tüketimi yapılmıştır. En fazla enerji tüketimi, ön ișlem uygulanmadan ve 60 ${ }^{\circ} \mathrm{C}$ 'de yapılan kurutma işleminde yapılmış olup değeri 1,782 kWh olarak belirlenmiştir. En düşük değerde enerji ise, $50{ }^{\circ} \mathrm{C}$ 'de zeytinyağı $/ \mathrm{K}_{2} \mathrm{CO}_{3}$ ön işlemi uygulanarak yapılan kurutma işleminde harcanmış olup değeri 0,680 kWh olarak belirlenmiștir. $50{ }^{\circ} \mathrm{C}$ ve $60{ }^{\circ} \mathrm{C}$ kurutma sıcaklıklarında, $\mathrm{NaOH}$ çözeltisinde haşlama ve zeytinyağı $/ \mathrm{K}_{2} \mathrm{CO}_{3}$ ön işlemi uygulanarak kapya biberlerin kurutma sürelerinden ve kümülatif tüketilen enerjiden sağlanan yüzde tasarruf miktarları belirlenmiş ve Tablo 2'de gösterilmiștir. $60{ }^{\circ} \mathrm{C}$ sıcaklıkta, $\mathrm{NaOH}$ ön işlemi uygulanarak yapılan kurutma işlemi, aynı sıcaklıktaki herhangi bir ön işlem uygulanmadan yapılan kurutma işlemine göre zamandan \%40,90, enerji tüketiminden \%39,17 tasarruf sağlamıştır. Zeytinyağı $/ \mathrm{K}_{2} \mathrm{CO}_{3}$ ön işlemi uygulanarak yapılan kurutma ișleminde ise zamandan $\% 59,10$, enerji tüketiminden $\% 54,75$ tasarruf sağlamıştır. 
DEÜ FMD 22(65), 331-342, 2020

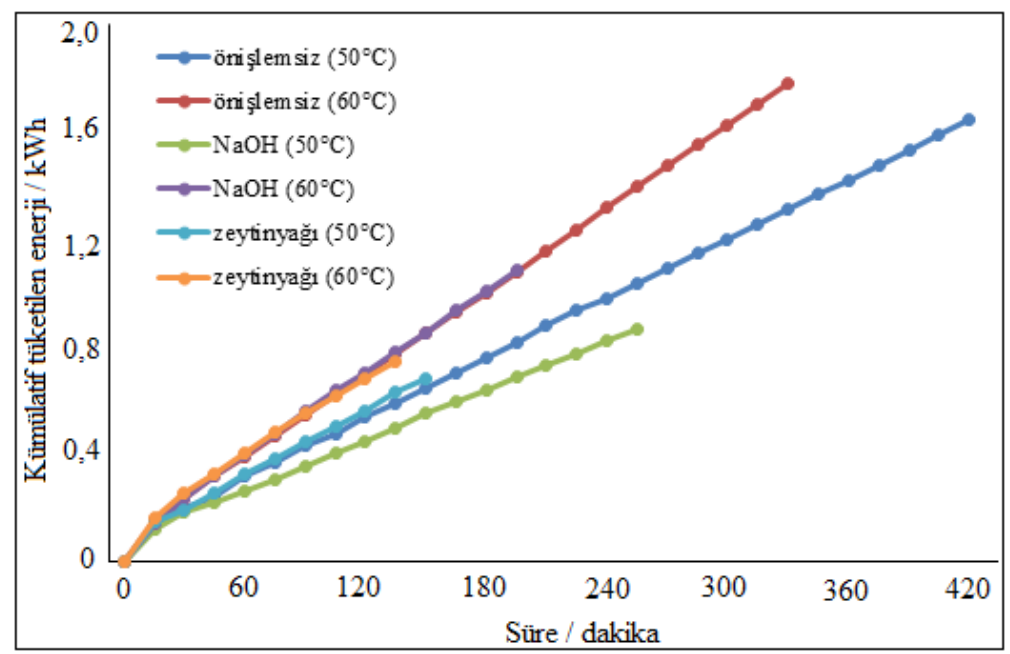

Şekil 8. Kapya biberlerinin kurutulma işlemlerinde zamana karşı çizilen kümülatif tüketilen enerji grafiği

Tablo 2. Uygulanan ön ișlem ve kurutma sıcaklığının sağlanan kuruma süresi ve enerjiden tasarruf üzerindeki etkisi

\begin{tabular}{cccc}
\hline \multirow{2}{*}{ Ön işlem } & Tasarruf & \multicolumn{2}{c}{$\%$ Tasarruf değerleri } \\
\cline { 2 - 4 } & & $50{ }^{\circ} \mathrm{C}$ & $60{ }^{\circ} \mathrm{C}$ \\
\hline \multirow{2}{*}{$\mathrm{NaOH}$} & Zaman & 39,28 & 40,90 \\
\cline { 2 - 4 } & Enerji & 47,29 & 39,17 \\
\hline Zeytinyağı $/ \mathrm{K}_{2} \mathrm{CO}_{3}$ & Zaman & 64,29 & 59,10 \\
\cline { 2 - 4 } & Enerji & 58,66 & 54,75 \\
\hline
\end{tabular}

\section{Tartıșma ve Sonuç}

Bu çalışmada, konvektif sıcak havalı kurutucuda kapya biberlerinin kurutulması ișleminde, biberlerin kurutma kinetiği, rehidrasyon kapasitesi ve kurutma işleminde kümülatif tükenen enerji üzerine, hava sıcaklığg ve ön işlemlerin etkisi incelenmiştir. Kurutma sıcaklığı arttıkça kapya biberlerin kuruma hızının arttığı ve bunun sonucu olarak da kuruma süresinin düștüğü gözlemlenmiștir. Kurutma öncesinde ön ișlem uygulamasının, kurutma süresini düşürmek üzerinde önemli ölçüde olumlu etkisi olduğu saptanmıştır. Ön işlem uygulanarak kurutulan kapya biberlerin efektif difüzyon katsayısı değerleri, ön işlem uygulanmadan kurutulanlara göre daha büyüktür. Ön işlemler uygulaması ile kurutulan kapya biberlerin rehidrasyon kapasitesi artmıștır. Ayrıca bu çalışmada kurutma sıcaklığı ve uygulanan ön işlemlerin kapya biberlerin kurutulması için harcanan kümülatif enerji üzerindeki etkisi incelenmiștir. Buna göre, en fazla enerji tüketiminin, $60^{\circ} \mathrm{C}^{\prime}$ de ön işlem uygulanmadan yapılan kurutma işleminde, en düşük değerde enerjinin ise, $50{ }^{\circ} \mathrm{C}$ 'de zeytinyağ $1 / \mathrm{K}_{2} \mathrm{CO}_{3}$ ön işlemi uygulanarak yapılan kurutma işleminde olduğu belirlenmiștir. Uygulanan ön işlem ve kurutma sıcaklığının sağlanan kuruma süresi ve enerjiden tasarruf üzerindeki etkileri özetlenmiştir. 
DEÜ FMD 22(65), 331-342 2020

\section{Teşekkür}

Çalışmaya destek veren Kimya Mühendisi Elif Begüm Yılmaz'a teșekkür ederiz.

\section{Kaynakça}

[1] Howard, L.R., Smith, R.T., Wagner, A.B., Villalon, B., Burns, E.E. 1994. Provitamin A and ascorbic acid content of fresh pepper cultivars (Capsicum annuum) and processed jalapenos. Journal of Food Science, 59, 362-365. DOI: 10.1111/j.13652621.1994.tb06967.x

[2] Simonne, A.H., Simonne, E.H., Eitenmiller, R. R Mills, H.A., Green, N. R. 1997. Ascorbic acid and provitamin A contents in unusually colored bell peppers (Capsicum annuum L.), Journal of Food Composition Analysis, Cilt. 10, s. 299-311. DOI: 10.1006/jfca.1997.0544

[3] Faustino, J.M.F., Barroca, M.J., Guine, R.P.F. 2007. Study of the drying kinetics of green bell pepper and chemical characterization, Food Bioprod. Process, Cilt. 85, s. 163-170. DOI: $10.1205 /$ fbp07009

[4] Göğüs, F. 1994. The effect of movement of solutes on maillard reaction during drying. Leeds University, $\mathrm{Ph} . \mathrm{D}$. thesis. Leeds.

[5] Dincer, I. 1998. Moisture loss from wood products during drying-Part I: moisture diffusivities and moisture transfer coefficients, Energy Sources, Cilt 20, s. 531-539. DOI: 10.1080/00908319808970044

[6] Aktaș, M., Gönen, E. 2014. Bay leaves drying in a humidity controlled heat pump dryer, Journal of the Faculty of Engineering and Architecture of Gazi University, Cilt. 29 (2), s. 433-441. DOI: 10.17341/gummfd.67707

[7] Karacaoğlu, C., Gürsoy, O., Yllmaz, Y. 2016. Ultrasonikasyon destekli vakum impregnasyon (emdirme) tekniği ile muamele işleminin kivi dilimlerinin kuruma kinetiği üzerine etkisi, Akademik Gıda, Cilt. 14 (3), s. 256-266.

[8] Aktaș, M., İlbaș, M., Yalçın, A., Sahin, M. 2013 Experimental investigation of drying behaviours in an infrared radiation dryer, Journal of the Faculty of Engineering and Architecture of Gazi University, Cilt. 28 (4), s. 767-775.

[9] Tuncer, I.K. 1995. How Kahramanmaras red pepper should be operated for internal market and external market, Sutcu Imam University Publications, Cilt. 11, s. 26-30.

[10] Oztekin, S., Bascetincelik, A., Soysal, Y. 1999. Crop drying programme in Turkey, Renewable Energy, Cilt. 16 (1-4), s. 789-79. DOI: 10.1016/S09601481(98)00282-1

[11] Demiray, M., Tülek, Y. 2008. Drying technology of tomatoes and some tomato antioxidant effects of compounds in the drying process, Electronic Journal of Food Technologies (GTED), 9-20.

[12] Torreggiani, D. 1993. Osmotic dehydration in fruit and vegetable processing, Food Research İnternational, Cilt. 26 (1), s. 59-68. DOI 10.1016/0963-9969(93)90106-SGet

[13] Ponting, J. 1973.0smotic dehydration of fruits: Recent modifications and applications, Process Biochemistry, Cilt. 8 (12), s. 18-20.
[14] Doymaz, I., Pala, M. 2002. Hot-air drying characteristics of red pepper, J. of Food Eng., Cilt. 55, s. 331-335. DOI:10.1016/S0260-8774(02)00110-3

[15] Hussain, I., Iqbal, M., Shakır, I., Ayub, N., Rawalakot, A.J. 2004. Effect of sucrose and glucose mixture on the quality characteristics of osmotically dehydrated banana slices, Pakistan Journal of Nutrition, Cilt. 3 (5), s. 282-284.

[16] Sunjka P., Raghavan G. 2004. Assessment of pretreatment methods and osmotic dehydration for cranberries, Canadian Biosystems Engineering, Cilt. 46 (1), s. 45-48.

[17] Pangavhane, D.R., Sawhney, R.L., Sarsavadia, P.N. 1999. Effect of various dipping pretreatment on drying kinetics of Thompson seedless grapes, Journal of Food Engineering, Cilt. 39 (2), s. 211-216. DOI:10.1016/S0260-8774(98)00168-X

[18] Christensen, R.A., Peacock, T.D. 1997. A guide to literature on reforming American Indian research, Tribal College, Cilt. 9 (1), s. 25-32.

[19] Xiao, H.W., Pang, C.L., Wang, L.H., Bai, J.W., Yang, W.X., Gao, Z.J. 2010. Drying kinetics and quality of Monukka seedless grapes dried in an airimpingement jet dryer, Biosyst. Eng., Cilt. 105 (2), s. $233-240$ 10.1016/j.biosystemseng.2009.11.001

[20] Wang Law, C.L., Nema, P.K., Zhao, J.H., Liu, Z.L.,Deng, L.Z., Gao, Z .J., Xiao, H.W. 2018. Pulsed vacuum drying enhances drying kinetics and quality of lemon slices, J. Food $\begin{array}{lll}\text { Eng., Cilt. } 224, & \text { s. 129-138. DOI: }\end{array}$ 10.1016/j.jfoodeng.2018.01.002

[21] Barbosa-Canovas, G.V., Vega-Mercado, 1996. H. Dehydration of Foods. First Edition, Chapmann Hall Publication. New York.

[22] Sacilik, K., Keskin, R., Elicin, A.K. 2006. Mathematical modeling of solar tunnel drying of thin layer organic tomato, J. Food Eng., Cilt. 73, s. 231-238. DOI:10.1016/j.jfoodeng.2005.01.025

[23] Liu, Q., Bakker-Arkema, F.W. 1997. Stochastic modelling of grain drying: Part 2. Model Development, Journal of Agricultural Engineering Research, Cilt. 66, s. 275-280. DOI:10.1006/jaer.1996.0145

[24] Crank, J. 1975. The mathematics of diffusion, Oxford University Press, OX, UK.

[25] Doymaz, İ. 2012. Evaluation of some thin-layer drying models of persimmon slices (Diospyos kaki L.), Energy Conversion and Management, Cilt. 56, s. 199-205. DOI:10.1016/j.enconman.2011.11.027

[26] Sobukola, O.P., Dairo, O.U., Odunewu, A.V. 2008. Convective hot air drying of blanched yam slices, International Journal of Food Science and Technology, Cilt. 43, s. 1233-1238. DOI:10.1111/j.1365-2621.2007.01597.x

[27] Aghbashlo, M., Kianmehr, M.H., Beygi, S.R.H. 2010. Drying and rehidration charactericstic of sour cherry (Prunus Cerasus L.), J. Food Process Preservation, Cilt. 34, s. 351-365. DOI:10.1111/j.1745-4549.2008.00310.x

[28] Feng, H., Tang, J. 1998. Microwave finish drying of diced apples in a spouted bed, Journal of Food Science, Cilt. 63, s. 679-683. DOI:10.1111/j.13652621.1998.tb15811.x 
DEÜ FMD 22(65), 331-342, 2020

[29] Doymaz, İ. 2018. Patlıcan dilimlerinin kurutma ve rehidrasyon karakteristiklerinin belirlenmesi, Gazi Üniversitesi Mühendislik-Mimarlı Fakültesi Dergisi, 33 (3), 833-841. DOI:10.17341/gazimmfd.416386

[30] TSE Standart detayı. https://intweb.tse.org.tr/Standard/Standard/Stan dard.aspx?0811180511151080511041191101040 550471051021200881110431131040730820850 49056050116083053072056088 (Erişim Tarihi: 27.03.2019).

[31] Darvishi, H., Asl, A. R., Asghari, A., Azadbakht, M., Najafi, G., Khodaei, J. 2014. Study of the drying kinetics of pepper, Journal of the Saudi Society of Agricultural Sciences, Cilt. 13, s. 130-138. DOI: 10.1016/j.jssas.2013.03.002

[32] Di Scala, K., Crapiste, G. 2008. Drying kinetics and quality changes during drying of red pepper, LWTFood Science and Technology, Cilt. 41, s. 789-795. DOI: 10.1016/j.lwt.2007.06.007

[33] Russo, P., Adiletta, G., Di Matteo, M. 2012. The influence of drying air temperature on the physical properties of dried and rehydrated eggplant, Food and Bioproducts Processing, Cilt. 91, s. 249-256. DOI:10.1016/j.fbp.2012.10.005

[34] Vega-Gálvez, A., Di Scala, K., Rodríguez, K., LemusMondaca, R., Miranda, M., López, J., Perez-Won, M. 2009. Effect of air-drying temperature on physicochemical properties, antioxidant capacity, colour and total phenolic content of red pepper (Capsicum annuum, L. var. Hungarian), Food Chemistry, Cilt 117, s. 647-653.

[35] Marques, L. G., Prado, M. M., \& Freire, J. T. 2009 Rehydration characteristics of freeze-dried tropical fruits, LWT-Food Science and Technology, Cilt. 42, s. 1232-1237. 